\title{
EDITORIAL
}

\section{Three Items of Special Interest}

After three years of service, Dr. T. N. Krishnamurti will be stepping down as cochief editor. Peter Ray will continue as chief editor for two more years. Both of us wish to acknowledge the outstanding contributions that have kept Monthly Weather Review a premier journal. We also acknowledge the key role, second only to that of the authors, of the reviewers that act as the vanguard of journal quality. Finally, we recognize the AMS Publications Department, which is constantly improving the time required to get manuscripts to press. We appreciate the support of our community in our effort to serve.

Monthly Weather Review has been the forum for a range of topics, but has for a long time been the principal journal in which methodologies related to numerous areas of meteorology have been published. These range from cloud scales to mesoscales and from the synoptic to the planetary scales. Time scales from 1 to 30 days are usually included. Observational and modeling papers are encouraged. It is recognized that these papers are also of interest to the oceanographic community, which shares similar approaches to modeling. Thus, Monthly Weather Review welcomes contributions of papers from the oceanographic community on modeling techniques and their applications that would be of interest to the geophysical modeling community. We have added a sixth editor, Dr. Mojib Latif, to help in this area. We encourage articles in this area to be submitted to Monthly Weather Review. Appropriate articles will be forwarded to Dr. Latif to handle as editor, after they have first been received by the office of the chief editor.

Later this year, a special issue on atmospheric electricity and lightning will be published. This was put together under the guest editorship of Professor Richard Orville. We hope that those of you in these communities will continue to want to reach the meteorological community by using the AMS journals.

All contributions to Monthly Weather Review should be sent to Chief Editor Peter Ray, P.O. Box 67012, Florida State University, Tallahassee, FL 32306. Papers related to weather analysis and forecasting, observed and modeled circulations, technique development, numerical ocean modeling, and verification studies are appropriate for $M W R$. The inside cover provides additional information and the procedure for submission. We have found that the use of electronic mail and faxes reduces the publication time, and we continue to encourage reviewers to use these media when practical.

We welcome your comments and suggestions for the continuing success of Monthly Weather Review in presenting the latest in theoretical, observational, and practical meteorology.

T. N. Krishnamurti Peter S. Ray 